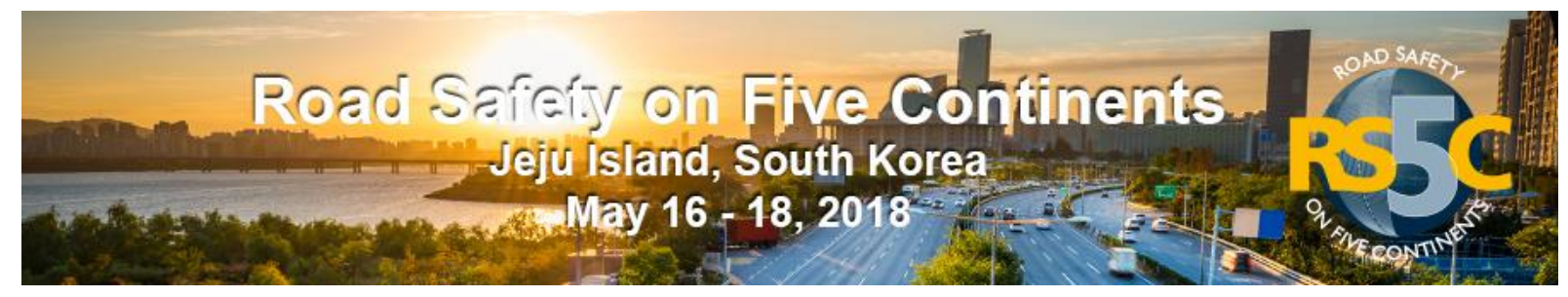

\title{
PEDESTRIAN-DRIVER COMMUNICATION AND DECISION STRATEGIES AT MARKED CROSSINGS
}

\author{
Matus Sucha \\ Department of Psychology, Palacky University in Olomouc, Krizkovskeho 8, Olomouc, 771 80, Czech \\ Republic, matus.sucha@upol.cz, tel.: 00420585633 501, fax: 00420585633700
}

\begin{abstract}
AIM
The aim of this work is to describe pedestrian-driver encounters, communication, and decision strategies at marked but unsignalised crossings in urban areas in the Czech Republic and the ways in which the parties involved experience and handle these encounters. The research questions we wanted to address in our study were: 1) What influences pedestrians' feeling of safety when crossing a road at a zebra crossing? 2) Which factors influence drivers' yielding behaviour and pedestrians' crossing behaviour, and how do they look at these situations, subjectively? 3) What are the aspects of the communication between drivers and pedestrians, and what are the sources of misunderstanding? 4) What are the circumstances and, possibly, the causes of the conflict situations observed?
\end{abstract}

\section{METHOD}

A mixed-methods design was used, consisting of focus groups with pedestrians and drivers regarding their subjective views of the situations, on-site observations, camera recordings, speed measurements, the measurement of car and pedestrian densities, and brief on-site interviews with pedestrians. We followed these steps: 1. Exploration of pedestrian and driver needs and conflict situations (identification of the problem) - focus groups with pedestrians and drivers (separately). 2. Pilot study. 3. Data collection: on-site observations (four sites - zebra crossing, in an urban area, three observers, 50 hours at each site), camera recordings ( 24 hours), speed measurement, measurement of car and pedestrian densities, and interviews (brief on-site interviews with pedestrians).

Four observation sites were selected - zebra crossings in the urban area of the city of Olomouc (approx. 100,000 inhabitants). The requirements for the sites were as follows: an unsignalised, marked pedestrian crossing; a two-lane street (one lane in each direction), and high pedestrian flow densities.

\section{RESULTS}

In close correspondence with the literature, our study revealed that the most relevant predictors of pedestrians' and drivers' behaviour at crossings were the densities of car traffic and pedestrian flows and car speed. The factors which influenced pedestrians' wait/go behaviour were: car speed, the distance of the car from the crossing, traffic density, whether there were cars approaching from both directions, various signs given by the driver (eye contact, waving a hand, flashing their lights), and the presence of other pedestrians. The factors influencing drivers' yield/go behaviour were (table 1): speed, traffic density, the number of pedestrians waiting to cross, and pedestrians being distracted. A great proportion of drivers (36\%) failed to yield to pedestrians at marked crossings. The probability of conflict situations increased with cars travelling at a higher speed, higher traffic density, and pedestrians being distracted by a different activity while crossing. 
Table 1: Factors influencing drivers' willingness to yield to a pedestrian at a crossing.

\begin{tabular}{|c|c|c|c|c|}
\hline Independent variable & $\begin{array}{l}\text { Odds } \\
\text { ratio }\end{array}$ & $\begin{array}{c}\text { Regression } \\
\text { weight }\end{array}$ & $\begin{array}{c}\text { Wald } \\
\text { statistic }\end{array}$ & $P$ value \\
\hline Intercept & 1.00 & 0.00 & 0.00 & 0.99 \\
\hline Car speed & 0.74 & -0.30 & $17.82 * * *$ & $<0.01$ \\
\hline Road traffic density & 0.86 & -0.15 & $4.52 *$ & 0.03 \\
\hline Pedestrian traffic density & 1.12 & 0.12 & 2.13 & 0.14 \\
\hline The car was less than 10 metres away & 0.49 & -0.71 & $25.45 * * *$ & $<0.01$ \\
\hline $\begin{array}{l}\text { A line of cars (more than five) was } \\
\text { approaching (driving in a platoon) }\end{array}$ & 1.65 & 0.50 & $16.37 * * *$ & $<0.01$ \\
\hline Demographic group & & & $40.42 * * *$ & $<0.01$ \\
\hline Child (0-12) & $\begin{array}{c}1.4 \\
2\end{array}$ & 0.35 & 0.68 & $\begin{array}{c}0.4 \\
1\end{array}$ \\
\hline Male (13-25) & $\begin{array}{c}1.1 \\
2\end{array}$ & 0.11 & 0.24 & $\begin{array}{c}0.6 \\
2\end{array}$ \\
\hline \multicolumn{5}{|l|}{ Male (26-65) (ref. group) } \\
\hline Female (13-25) & $\begin{array}{c}1.2 \\
4\end{array}$ & 0.22 & 1.28 & $\begin{array}{c}0.2 \\
6\end{array}$ \\
\hline Female (26-65) & $\begin{array}{c}0.9 \\
6\end{array}$ & -0.04 & 0.03 & $\begin{array}{c}0.8 \\
5\end{array}$ \\
\hline Senior citizen $(65+)$ & $\begin{array}{c}2.6 \\
7\end{array}$ & 0.98 & 2.26 & $\begin{array}{c}0.1 \\
3\end{array}$ \\
\hline $\begin{array}{l}\text { Group of pedestrians (more than three } \\
\text { pedestrians) }\end{array}$ & $\begin{array}{c}2.8 \\
2\end{array}$ & 1.04 & $\begin{array}{l}24.4 \\
9 * * *\end{array}$ & $\begin{array}{c}< \\
0.0 \\
1\end{array}$ \\
\hline $\begin{array}{l}\text { The pedestrian stood waiting more than } 0.5 \\
\text { metres away from the kerb. }\end{array}$ & 0.35 & -1.06 & $6.64 * * *$ & 0.01 \\
\hline $\begin{array}{l}\text { The pedestrian used at least eye contact to } \\
\text { give the driver a sign. }\end{array}$ & 2.39 & 0.87 & 2.04 & 0.15 \\
\hline Waiting time of the pedestrian & & & $62.45 * * *$ & $<0.01$ \\
\hline \multicolumn{5}{|l|}{ The pedestrian didn't wait. (ref. group) } \\
\hline The pedestrian waited less than five seconds. & $\begin{array}{c}2.0 \\
8\end{array}$ & 0.73 & 3.60 & $\begin{array}{c}0.0 \\
6\end{array}$ \\
\hline $\begin{array}{l}\text { The pedestrian waited more than five } \\
\text { seconds. }\end{array}$ & $\begin{array}{c}0.3 \\
5\end{array}$ & -1.04 & $\begin{array}{l}55.3 \\
3 * * *\end{array}$ & $\begin{array}{c}< \\
0.0 \\
1\end{array}$ \\
\hline $\begin{array}{l}\text { The driver engaged in other activities while } \\
\text { driving. }\end{array}$ & 1.81 & 0.59 & 0.95 & 0.33 \\
\hline $\begin{array}{l}\text { The pedestrian engaged in other activities } \\
\text { while crossing the road. }\end{array}$ & 0.68 & -0.39 & $5.24^{*}$ & 0.02 \\
\hline
\end{tabular}

Note: The dependent variable Drivers' willingness to yield was coded as one when the driver yielded and zero otherwise. The variables Car speed, Road traffic density, and Pedestrian density were standardised to a $\mathrm{z}$-score. Statistical significance notation: $* \mathrm{p}<0.05, * * \mathrm{p}<0.01, * * * \mathrm{p}<0.001$. 


\section{Road Ezifít on Five Continentis}

Jeju island, South Korea

May $16-18,2018$

\section{CONCLUSIONS}

The findings of this study can add to the existing literature by helping to provide an understanding of the perception of encounter situations by the parties involved and the motives lying behind certain aspects of behaviour associated with these encounters. This seems necessary in order to develop suggestions for improvements. For instance, the infrastructure near pedestrian crossings should be designed in such a way as to take proper account of pedestrians' needs to feel safe and comfortable, as well as ensuring their objective safety. Thus, improvements should include measures aimed at reducing the speed of approaching vehicles (e.g. humps, speed cushions, elevated crossings, early yield bars, and narrow lanes), as this would enhance yielding by motor vehicles. Other measures that specifically rely on the subjective perception of different situations by the parties involved include the education and training of drivers, the aim of which is to promote their understanding and appreciation of pedestrians' needs and motives. 